\title{
Separation and Identification of the Major $C_{7}$ to $C_{10}$ Components of Triptene Residue
}

\author{
By Philip Pomerantz, Thomas W. Mears, and Frank L. Howard
}

\begin{abstract}
As a part of an investigation conducted under the auspices of the National Advisory Committee for Aeronautics, the Bureau of Aeronautics of the Department of the Navy, and the Department of the Air Force, embracing the synthesis and isolation of highly branched hydrocarbons, a series of systematic distillations was carried out on "triptene residue," a synthetic alkylate made at the Radford Laboratories of the General Motors Corporation.

This report describes the isolation thereby of two heptenes, four octenes, and three nonenes; the identification of four heptenes, two octenes, three nonenes, and six decenes not resolvable by fractional distillation; and the isolation of two heptanes, two octanes, one nonane, and five decanes formed by hydrogenation of mixtures of olefins. Physical constants for the isolated products and graphs showing the course of the several distillations are presented.

The analysis presented is based, where individual olefins were isolated, on the distillation curves; where the mixtures obtained by distillation were more complex, the analysis is based on ozonolysis data and/or distillation data of the hydrogenated product.

The mechanism of successive methylation by which the several olefins in the mixture were derived has been shown to be valid.
\end{abstract}

\section{Introduction}

The work described herein is part of an investigation conducted for the National Advisory Committee for Aeronautics, the Bureau of Aeronautics of the Department of the Navy, and the Department of the Air Force on the synthesis and purification of highly branched hydrocarbons for the determination of their physical properties and for a study of their antiknock characteristics. This report describes the isolation and physical properties of a number of hydrocarbons obtained from triptene residue by systematic fractionation and the identification of several others not isolated.

Triptene residue is a byproduct of the manufacture of 2,3,3-trimethyl-1-butene (triptene). The details of the process and the mechanism of the chemical reactions involved have been presented $[22]^{1}$ by Verle A. Miller and W. G. Lovell.

1 Figures in brackets indicate the literature references at the end of this paper.
As shown by Miller and Lovell, the process consists essentially of reacting methyl chloride with the dehydration products of tertiary amyl alcohol, in the presence of a specially prepared lime, to yield hydrocarbons of higher molecular weight.

The olefin reactants consist primarily of 2 methyl-2-butene and lesser amounts of 2-methyl1-butene and 3-methyl-1-butene. Under the proper conditions, the olefins are methylated at the double bond to yield a more complex mixture of hexenes. The first step in the methylation is believed to proceed as illustrated below. ${ }^{2}$
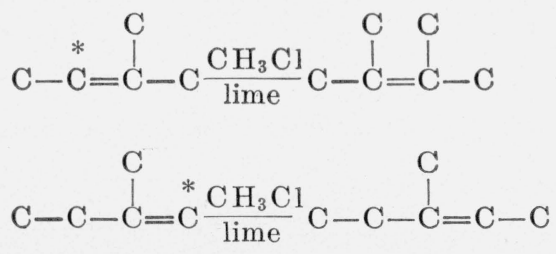

${ }^{2}$ Asterisks indicate point of methylation. 
The hexenes can react further to yield heptenes, the most important of these being triptene. This methylation step is shown below.

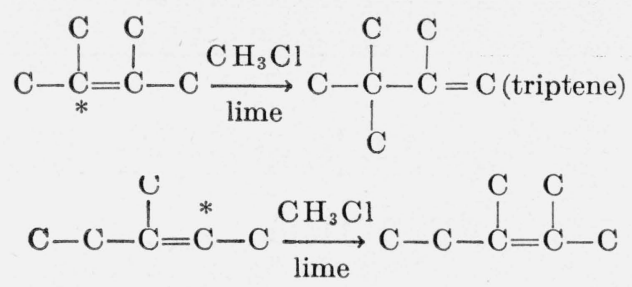

Successive, stepwise methylations of portions of the heptenes yield octenes, nonenes, decenes, and higher boiling materials.
Figure $1^{3}$ shows the postulated course of the methylations of the methylbutenes and the olefins isolated and/or identified in this work.

The compound 2,3,3-trimethyl-1-butene (triptene) is the component of the methylation products that is of the greatest interest, the methylation reaction being used primarily to produce this olefin. Besides having a high knock-rating, triptene is the precursor, by hydrogenation, of $2,2,3-$ trimethylbutane (triptane), a compound having exceptional engine behavior. Large amounts of

3 This figure was adapted from the one published by Miller and Lovell [22]. This altered chart is reproduced by permission of the Editor of Industrial and Engineering Chemistry.

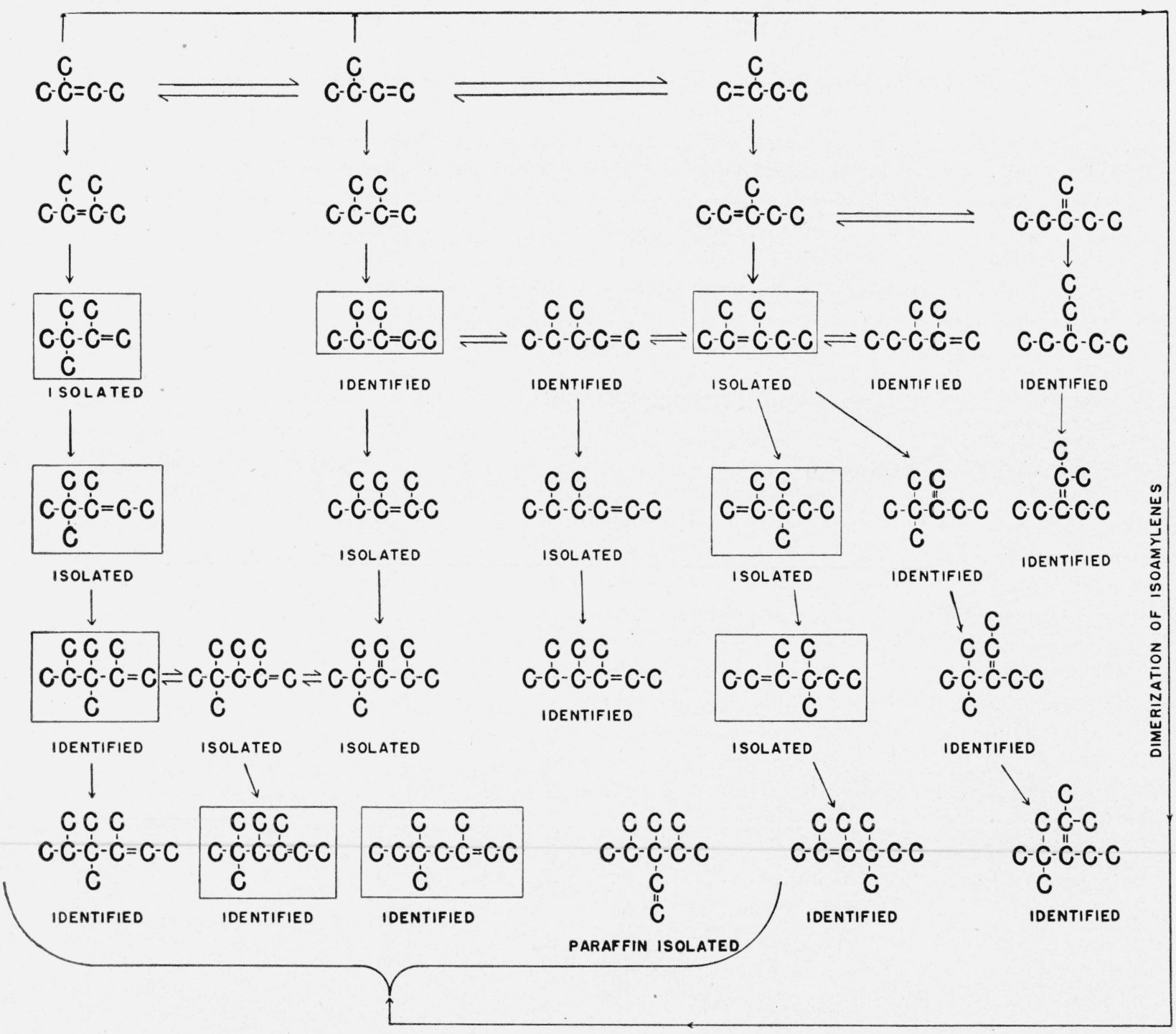

FiguRE 1. Olefins isolated or identified in triptene residue.

Principle products are enclosed by rectangles. 
triptene were made by methylation at the Redford Laboratories of the General Motors Corporation, separated from the reaction mixture by distillation, and then hydrogenated to triptane. The "bottoms" from this distillation is designated as triptene residue.

The identity of the components of triptene residue aroused considerable interest at the Redford Laboratories, because the verification of the presence of certain structures as formulated in figure 1 would throw light on the mode of methylation. The work that had been done on this problem at the Redford Laboratories had been performed on the hydrogenated heptene and octene portions. More conclusive evidence, in the form of the identification of olefins, was needed, particularly in the nonene and decene range.

In addition, interest was directed in this laboratory to the composition of triptene residue because several highly branched members shown in figure 1 were needed in large quantities for engine tests and for synthetic work, and this alkylate appeared to be the most promising source of these compounds. Accordingly, by arrangement with General Motors Corporation, work was started on the fractionation of triptene residue in order to identify the major constituents of the alkylate through the decene range, and to isolate any hydrocarbons that could be obtained by fractional distillation.

\section{Equipment and Methods}

\section{Distillation Equipment}

There were seven stills available for this study; these are listed in table 1. A more complete description of these stills is given in a previous report [14]. Still 9, having an efficiency of about 40 theoretical plates at total reflex, was used for the fractionation of the oily layer arising from the ozonization of fractions of triptene residue.

TABLE 1. Distillation columns

\begin{tabular}{|c|c|c|c|c|c|c|c|}
\hline $\begin{array}{l}\text { Still } \\
\text { num. } \\
\text { ber }\end{array}$ & Type & Size & $\begin{array}{l}\text { Material of con- } \\
\text { struction }\end{array}$ & Packing & $\begin{array}{l}\text { Number } \\
\text { of theo- } \\
\text { retical } \\
\text { plates } \\
\text { (approx.) }\end{array}$ & $\begin{array}{l}\text { Operat- } \\
\text { ing reflux }\end{array}$ & $\begin{array}{l}\text { Pot ca- } \\
\text { pacity }\end{array}$ \\
\hline 9 & $\begin{array}{l}\text { Total reflux variable take- } \\
\text { off. }\end{array}$ & 16 by $1 / 3 n$ & Glass & $\begin{array}{l}364 \text {-in. stainless steel helices made from } \\
0.006 \text {-in. wire. }\end{array}$ & 40 & Liters/hr. & $\begin{array}{r}\text { Gal. } \\
0.1\end{array}$ \\
\hline 11 & -....do do & 240 by $2 \ldots$ & Monel ............. & $\begin{array}{l}\text { 3/32-in. stainless steel helices made from } \\
0.010 \text {-in. wire. }\end{array}$ & 65 & 4 to $6 \ldots$ & 15 \\
\hline 12 & -....do_....... & 600 by $4 \ldots$ & Galvanized steel... & 38-in. unglazed porcelain raschig rings..... & 100 & 45 to 50. & 55 \\
\hline 13 & - $\mathrm{d}_{0}$ & 600 by $4 \ldots \ldots$ & .....do do & - do & 100 & 45 to $50 \ldots$ & 55 \\
\hline 14 & - & 600 by $2 \ldots \ldots$ & Stainless steel..... & $\begin{array}{l}\text { 3/32.in. stainless steel helices made from } \\
0.010 \text {-in. wire. }\end{array}$ & 200 & 4 to $6 \ldots$ & 35 \\
\hline 17 & Podbelniak Hypercal..... & 72 by $1 \ldots$ & Glass................ & Heli-Grid . . & 100 & 2 to $3 \ldots$ & 1 \\
\hline 22 & $\begin{array}{l}\text { Total reflux variable take- } \\
\text { off. }\end{array}$ & 72 by 1 & . do & 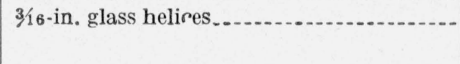 & 35 & 2 to $3 \ldots$ & 1 \\
\hline
\end{tabular}

Stills 11 to 14 , inclusive, are of the total condensation partial-takeoff type and were constructed for analysis of commercial crudes, purification of large amounts of materials, and for isolation of hydrocarbons from commercial mixtures. Stills 12,13 , and 14 were used to process the bulk of the triptene residue, whereas still 11 was used for redistillation of several cuts and for the isolation of paraffins from several of the hydrogenated cuts. Still 17 was used for analytical distillation of small amounts of material and of hydrogenated cuts and for redistillation of "heart cuts" of the several plateaus obtained from distillation of the triptene residue.

Still 22 is a glass column of the Whitmore-Lux type; it was used for exploratory distillations of material as received from the General Motors Corporation.

\section{Fractionations}

The material available for the present study was a 980-gallon shipment from the Redford Laboratories, which consisted of triptene residue, as defined previously, containing all of the material from the methylation product boiling above triptene.

An exploratory distillation of a 2,850-ml sample of triptene residue as received was conducted in still 22 at a reflux ratio of 25 to 1 . This was done to serve as a guide in conducting the later distilla- 
tions of large quantities of material. The results obtained from this distillation of triptene residue are shown in figure 2 .

Since this preliminary test showed that the triptene residue could be separated readily into four portions containing, respectively, heptenes, octenes, nonenes, and decenes, a series of distillations were performed on the bulk of the material in stills 12 to 14 inclusive, and at a reflux ratio of 25 to 1 , to separate the entire material and to obtain larger quantities for subsequent investigation. In this series of distillations, material boiling in the range $75^{\circ}$ to $171^{\circ} \mathrm{C}$ from each run of trip- the triptene residue. These fractions are listed below:

\begin{tabular}{|c|c|c|c|}
\hline Fraction & Boiling point range & Volume & Volume \\
\hline & ${ }^{\circ} C$ & gal & $\%$ \\
\hline 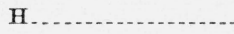 & 75 to 100 & 320 & 33 \\
\hline $\mathrm{O}_{\ldots} \ldots$ & 100 to 118 & 390 & 40 \\
\hline$N_{\ldots} \ldots$ & 118 to 143 & 54 & 5 \\
\hline D & 143 to 171 & 98 & 10 \\
\hline Residue and loss...... & - & 118 & 12 \\
\hline
\end{tabular}

Each of the four portions, $\mathrm{H}, \mathrm{O}, \mathrm{N}$, and $\mathrm{D}$ was redistilled at a reflux ratio of about 100 to 1 in stills 12 and 13 . In several cases, plateaus

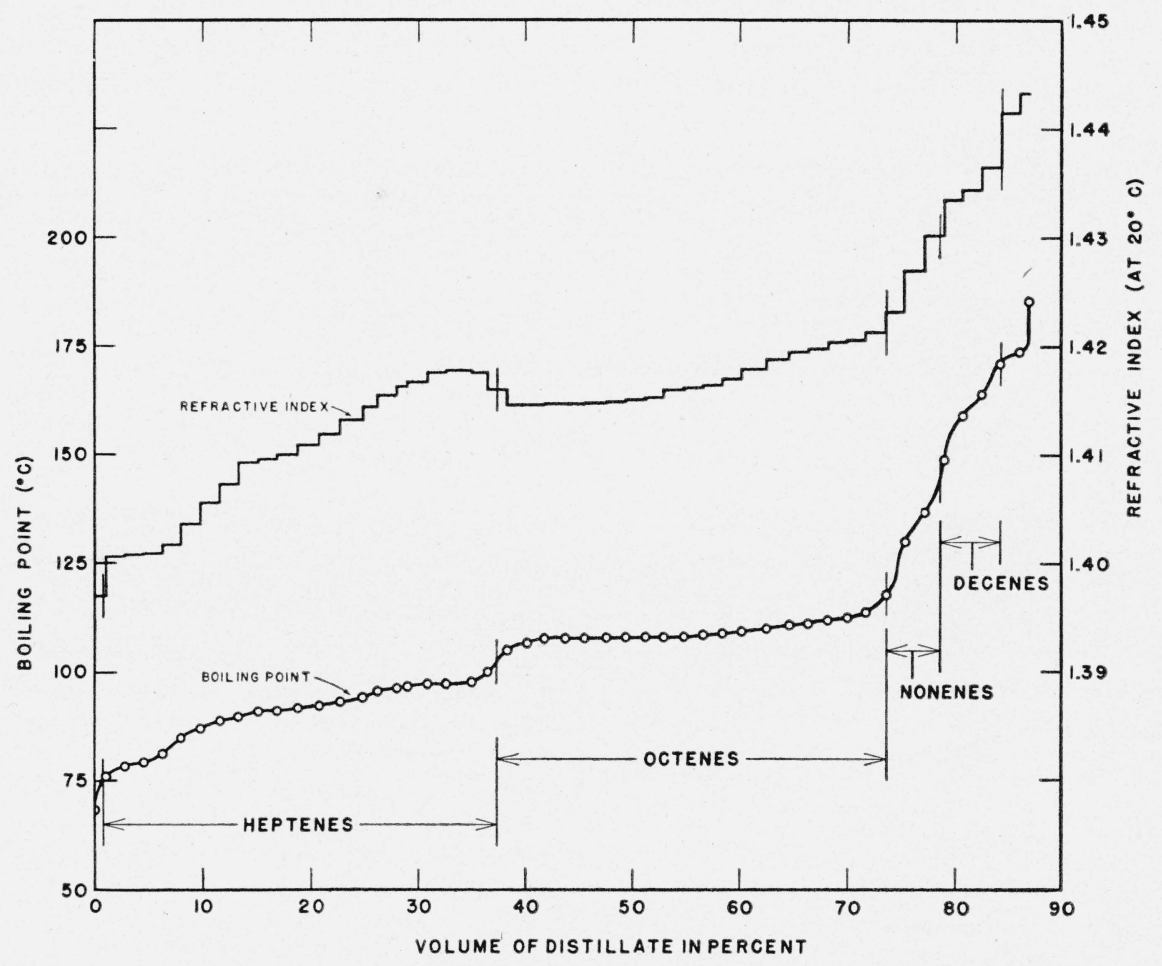

Figure 2. Exploratory distillation of triptene residue as received.

tene residue was collected in 1-quart samples. (Distillation was carried out to $171^{\circ} \mathrm{C}$ in order to assure inclusion of all the decenes). Corresponding fractions from the several distillations were then combined. This operation yielded four major fractions designated as $\mathrm{H}, \mathrm{O}, \mathrm{N}$, and $\mathrm{D}$, which were concentrates, respectively, of the heptene, octene, nonene, and decene portions of representing relatively pure substances were obtained. Figures 3 to 6 represent the results of this operation. In this series of distillations, the residue of the heptene cut was added to the octene cut; the residue from this was added to the nonene portion, and so on. Table 2 lists some of the physical properties of the plateaus obtained from this series of redistillations. 


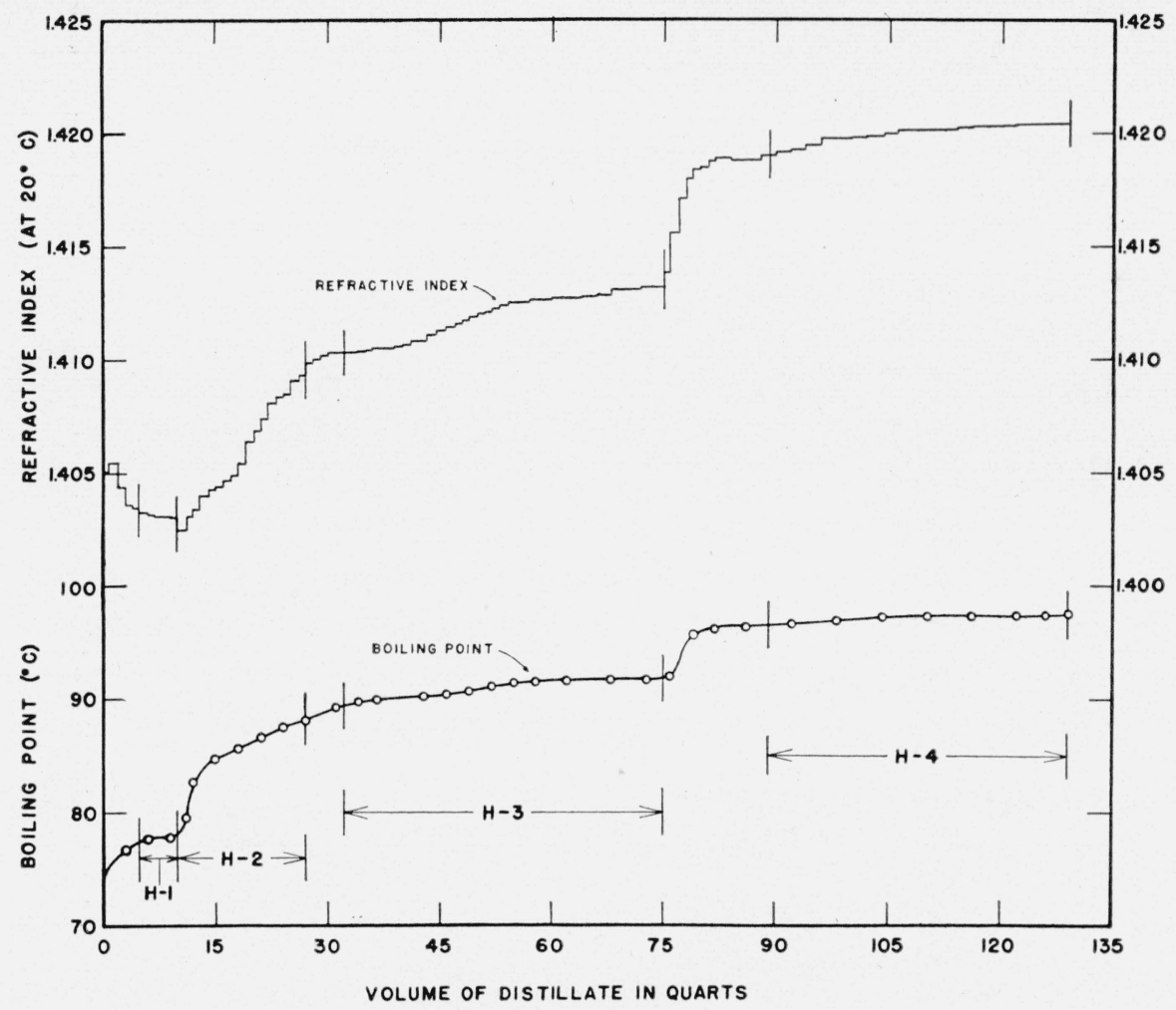

Figure 3. Redistillation of the preliminary heptene cut.

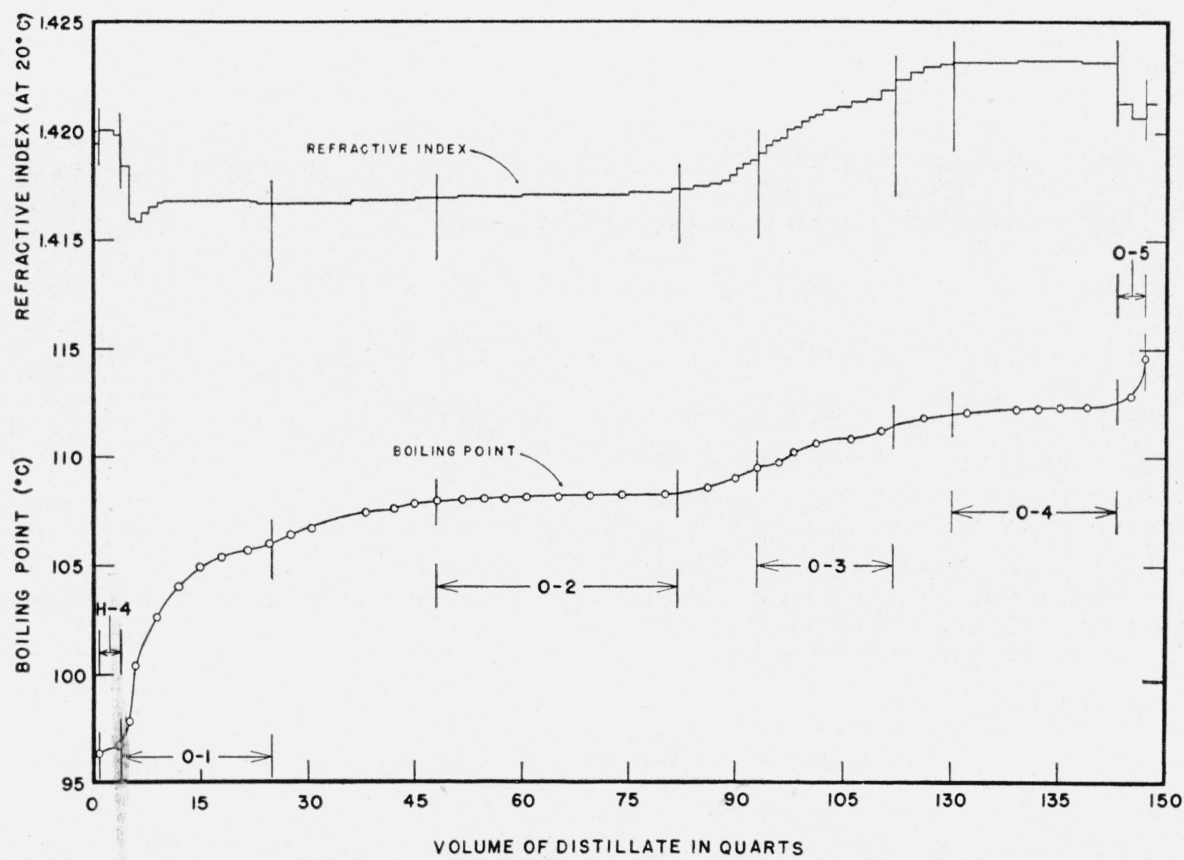

Figure 4. Redistillation of the preliminary octene cut. 
TABLE 2. Separation and iden

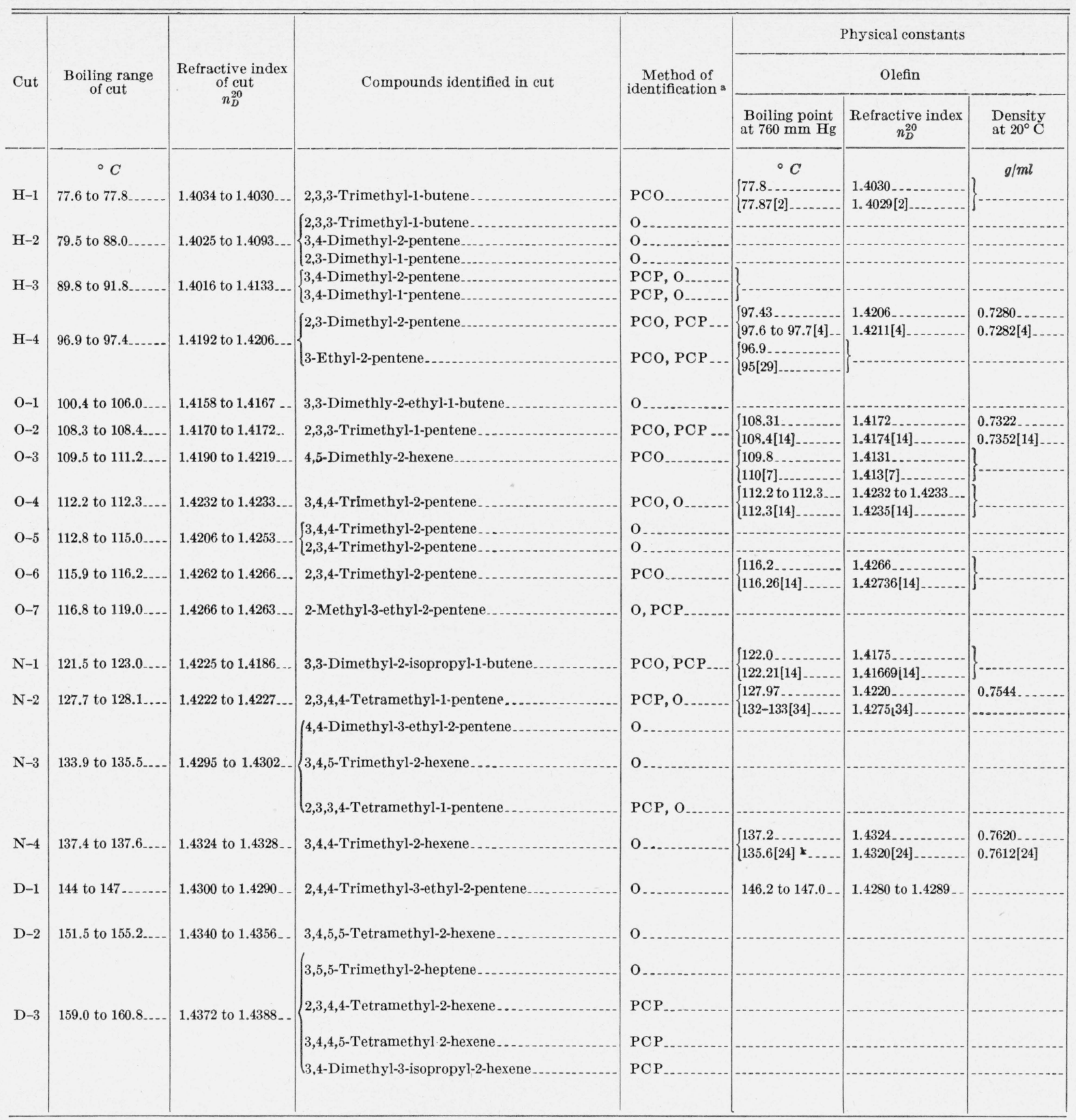

s. The abbreviations and their significance are: $\mathrm{PCO}$, material identified by the physical constants of the olefin; PCP, material identified by physical constants of the paraffin formed by hydrogenation of the olefin; $O$, material identified by ozonolysis.

b The letter $\mathbf{M}$ after the melting point of the derivative indicates that no depression of melting point occurred when the derivative was mixed with an authentic sample. c Identifications of acetaldehyde, formaldehyde, and acetone, if any, are described in the text. Only the larger fragments from ozonolyses are included here.

d Semicarbazone of 3,4,4-trimethyl-2-pentanone, $\mathrm{mp}$ (found) $150^{\circ}$ to $150.5^{\circ}$ $\mathrm{C}, \mathrm{mp}$ (lit) [34] $151^{\circ} \mathrm{C}$, [8] $148^{\circ} \mathrm{C}$.

e Semicarbazone of 2,2-dimethyl-3-pentanone, $\mathrm{mp}$ (found) $143.5^{\circ}$ to $145^{\circ} \mathrm{C}$ $\mathrm{mp}$ (lit) [18] $144^{\circ} \mathrm{C}$. The mixed melting point was determined with 2,4- 


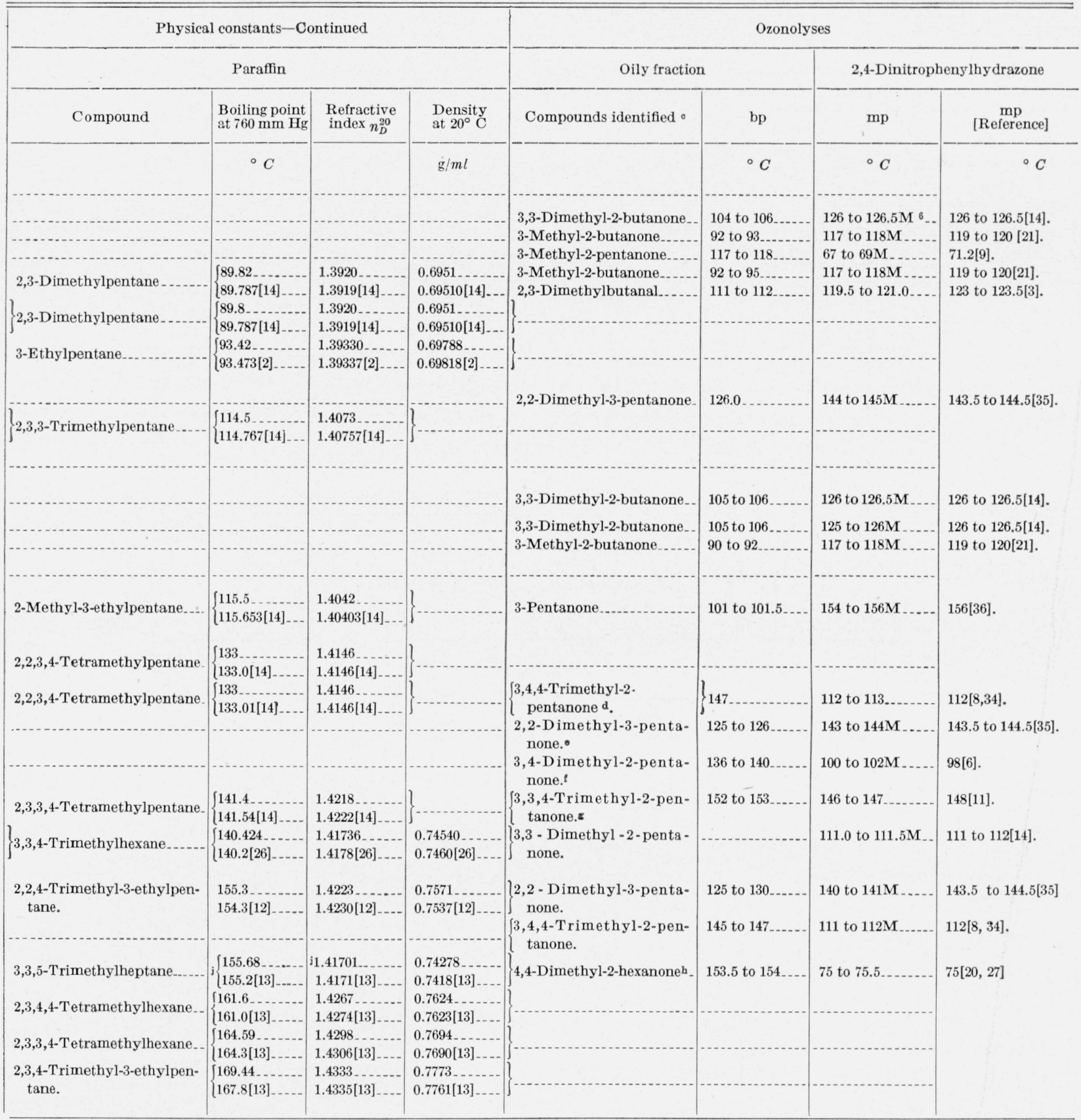

dinitrophenylhydrazone of a synthetically prepared sample of ketone. Kharasch et al [19] report the 2,4-dinitrophenylhydrazone $\mathrm{mp}$ to be $175^{\circ} \mathrm{C}$, which is believed to be in error.

A A somewhat impure sample of this 2,4-dinitrophenylhydrazone was kindly supplied by Dr. Cook [6]. A mixed melting point determination showed no depression.

. Semicarbazone of 3,3,4-trimethyl-2-pentanone, $\mathrm{mp}$ (found) $147^{\circ}$ to $148^{\circ} \mathrm{C}$, $\mathrm{mp}$ (lit) [11] $150.5^{\circ}$ to $151^{\circ} \mathrm{C}$, [5] $150^{\circ} \mathrm{C}$. s Semicarbazone of 4,4-dimethyl-2-hexanone, $\mathrm{mp}$ (found) $170^{\circ}$ to $171^{\circ} \mathrm{C}$, mp (lit) [8] $169.5^{\circ} \mathrm{C}$, [27] $169^{\circ}$ to $170^{\circ} \mathrm{C}$. Drake et al [8] report the 2,4-dinitrophenylhydrazone to be $146.5^{\circ}$ to $147^{\circ} \mathrm{C}$, which is believed to be in error.

j Drake and Welsh [10] obtained a boiling point of $159.1^{\circ} \mathrm{C}$ and a refractive index (corrected to $20^{\circ} \mathrm{C}$ ) of 1.4230 . These values are at variance with those from other investigators [12], [17] and are believed to be in error.

k Measured at a pressure of $738 \mathrm{~mm} \mathrm{Hg}$. 


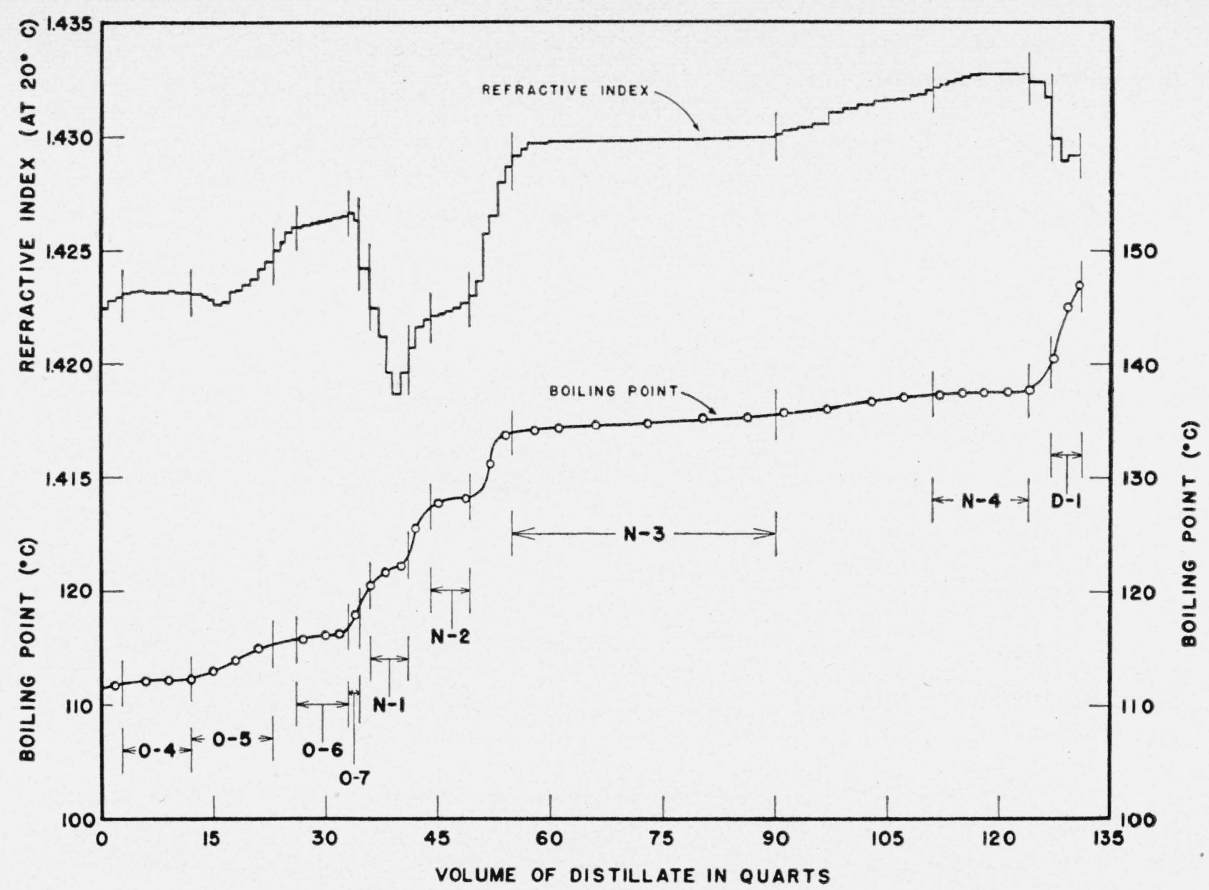

Figure 5. Redistillation of the preliminary nonene cut.

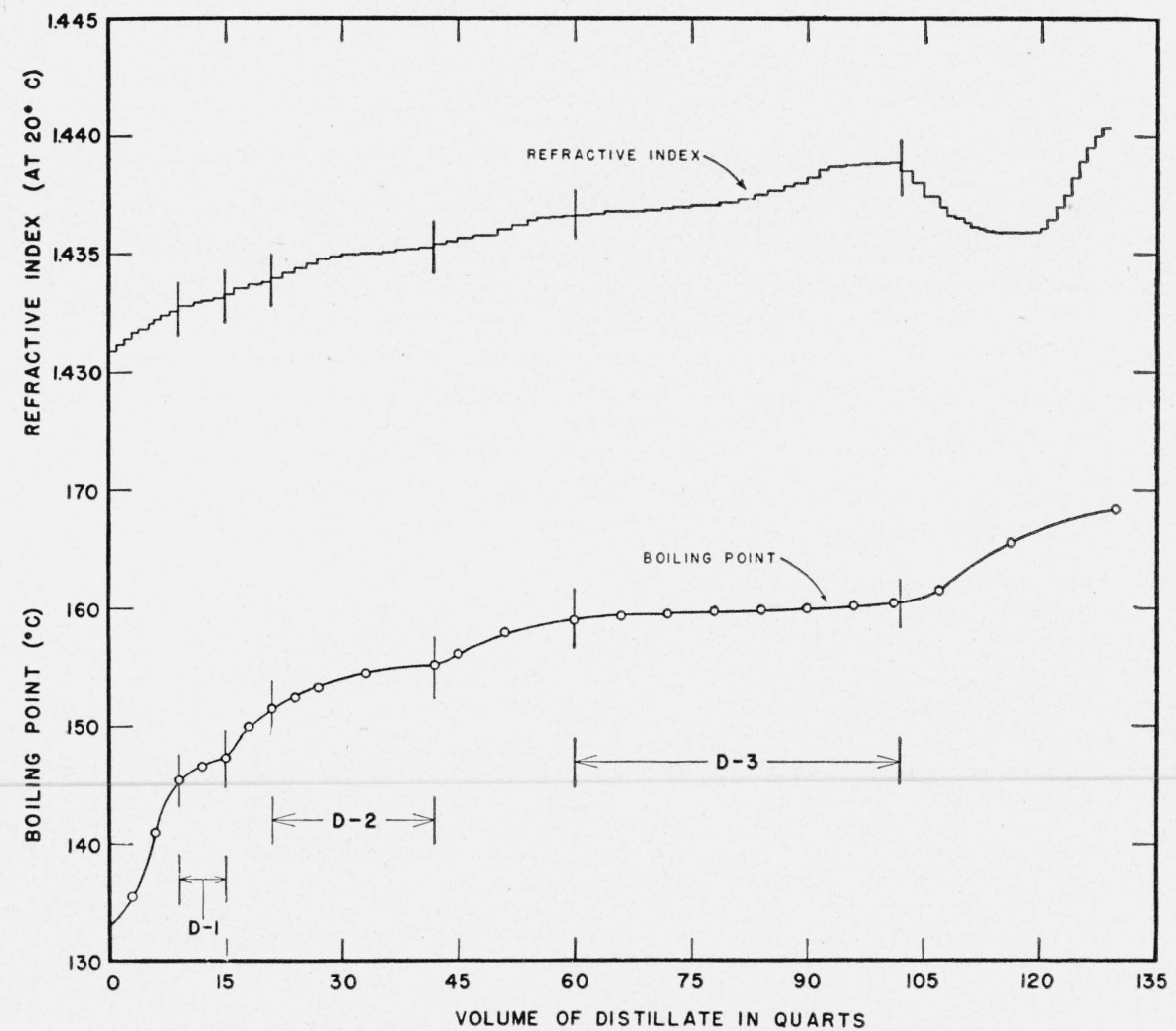

FiguRE 6. Redistillation of the preliminary decene cut. 
Figure 3 shows the course of one of the redistillations of the heptene portion. This graph, which represents a typical redistillation of this preliminary cut, shows the boiling points and refractive indices (at $20^{\circ} \mathrm{C}$ ) of the distillate, in relation to the volume distilled.

In a similar fashion, figure 4 shows data obtained from redistillation of a part of the octene portion in still 12. Again, this is a typical redistillation of the octenes and shows most of the components present in the octene range. Because of the relatively large hold-up of still 12 and the large pot capacity with the resulting large residue, some of the higher boiling octene components are not shown in figure 4. However, the residue from the distillations represented by figure 4 was added to the charge of nonenes and the combined charge distilled. Figure 5 shows the distillation of a part of the preliminary nonene fraction. Because of the system of amplified distillation used, the octene components not shown in figure 4 are presented in this graph. Similarly, figure 6 shows the redistillation of a portion of the decenes.
Analyses were performed on each of the cuts listed in table 2 and shown in figures 3 to 6 , inclusive. If the plateau represented a reasonably pure compound with well-known physical constants, the identification of the cut was made by comparison of the measured physical properties with the literature values. Where the plateau was a mixture, or a compound with literature values not clearly established, hydrogenation and/or ozonolysis were used to establish the identity of the components. Moreover, wherever a reasonably pure compound was obtained, a "heart cut" was redistilled in column 17 to obtain a sample for the measurement of physical constants.

The analysis of the triptene residue, which is shown in table 3 , was based primarily on distillation date and is only approximate. For complex fractions, analytical distillation of the hydrogenated cuts was used. Ozonolysis data can be relied on only for qualitative information, inasmuch as several cuts were markedly resistant to ozonization.

TABLE 3. Analysis of triptene residue

\begin{tabular}{|c|c|c|c|c|}
\hline Cut & Boiling range & $\begin{array}{l}\text { Percentage } \\
\text { of triptene } \\
\text { residue }\end{array}$ & Compounds in cut a & $\begin{array}{l}\text { Percent } \\
\text { of com- } \\
\text { pounds in } \\
\text { cut b }\end{array}$ \\
\hline $\begin{array}{l}\text { Undecenes and higher boiling sub- } \\
\text { stances. }\end{array}$ & 75 to 100 & 40 & 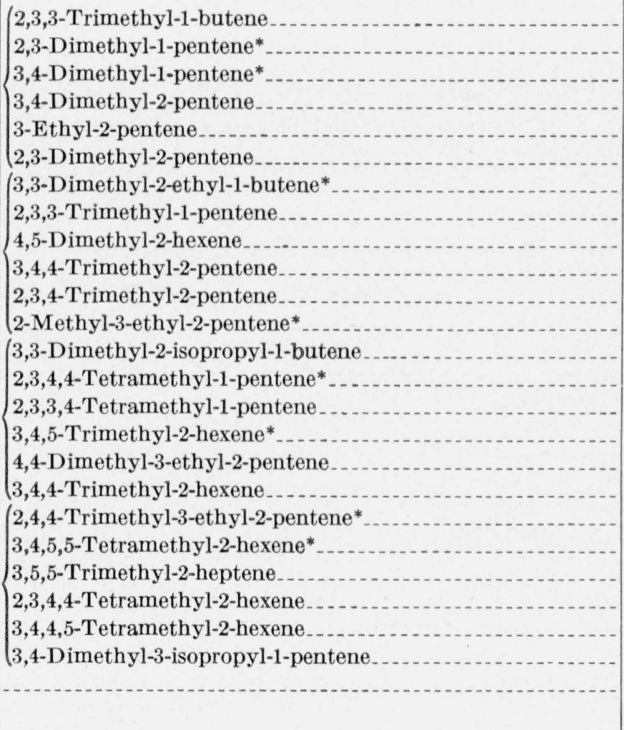 & $\begin{array}{r}5 \\
5 \\
40 \\
5 \\
45 \\
10 \\
45 \\
2 \\
35 \\
6 \\
2 \\
5 \\
10 \\
45 \\
10 \\
30 \\
5 \\
35 \\
50 \\
5 \\
4 \\
1\end{array}$ \\
\hline
\end{tabular}

s The asterisks indicate the presence of small amounts of unknown component.

b This analysis is an estimate and is based on distillation analysis and hydrogenation data. 


\section{Hydrogenations}

The hydrogenation reactions were accomplished in rocking-autoclaves of the type described by Adkins [1]. These were of 1-, 3-, and 20-liter capacity. The catalyst used was a commercial nickel-on-kieselguhr. The hydrogenations were carried out at 1,000 to $2,000 \mathrm{lb} / \mathrm{in}^{2}{ }^{2}$ pressure and at a temperature of $140^{\circ}$ to $190^{\circ} \mathrm{C}$. Several of the cuts contained chlorides in small amounts; and hydrogenation of these proved to be somewhat more difficult than for chloride-free olefins, thus necessitating longer periods for completion. Not infrequently, several treatments were necessary to obtain a saturated product. Hydrogenated cuts were passed through silica gel and distilled in column 11 or 17 for analysis.

\section{Ozonolyses}

The apparatus used for the several ozonolyses was essentially equivalent to that described by Whitmore and Church [32]. Generally, ozonizations were performed on 0.5 -mole samples. The solvent used was petroleum ether that had been washed successively with concentrated sulfuric acid, water, sodium bicarbonate, dried over calcium chloride, and distilled. The portion boiling between $35^{\circ}$ and $40^{\circ} \mathrm{C}$ was passed through silica gel. Ozonization of 0.5 -mole sample in $300 \mathrm{ml}$ of solvent at $-5^{\circ}$ to $-15^{\circ} \mathrm{C}$ was generally accomplished in 14 to $16 \mathrm{hr}$, although a few olefins were ozonized in less time. In most cases the solvent was not removed prior to decomposition. The ozonide was decomposed with $40 \mathrm{~g}$ of zinc and $500 \mathrm{ml}$ of water containing traces of silver nitrate and hydroquinone.

The water layer from the decomposition was always tested for the presence of formaldehyde and acetone. The formaldehyde in the ozonolyses products was identified as its dimethone derivative (mp $188^{\circ}$ to $190^{\circ} \mathrm{C}$ ) [15], the acetone by conversion to its dibenzal derivative $\left(\mathrm{mp} 111^{\circ}\right.$ to $112^{\circ} \mathrm{C}$ ) [16].

The material obtained in the ether trap was tested for acetaldehyde by reaction with ammonia, with the subsequent formation of the acetaldehydeammonia crystalline complex (mp $86^{\circ}$ to $88^{\circ} \mathrm{C}$ ) [33].

The oily distillate from the decomposition of the ozonide was dried over sodium sulfate and distilled in column 9 . The relatively pure frac- tions from the latter distillation were converted to the semicarbazone and/or the 2,4-dinitrophenylhydrazone for purposes of identification. Orthodox qualitative tests were performed on selected cuts from the oily layer distillation, prior to reaction with derivative-forming reagents.

Aldehydes and ketones were generally identified either by the melting-point values of two derivatives, or by the melting point of one derivative and absence of any depression of the melting point when the unknown was mixed with an authentic sample of known compound.

The results from the ozonization of some of the lower boiling compounds were semiquantitative, but resistance to ozone of some of the higher boiling, highly branched compounds did not warrant even rough approximation by this method of the relative amounts of isomers in the material ozonized.

Ozonolysis of cut $\mathrm{H}-2$, the second concentrate of the heptene fraction is typical and is described as an example. This cut boiled in the range $79.5^{\circ}$ to $88.0^{\circ} \mathrm{C}$ and was a rather complex mixture of heptenes boiling above triptene (bp $77.8^{\circ} \mathrm{C}$ ) and below 3,4-dimethyl-2-pentene (bp about $90^{\circ} \mathrm{C}$ ):

Treatment of $50 \mathrm{~g}$ of the cut $\mathrm{H}-2$ with 8 percent of ozone in oxygen at 12.5 liters $/ \mathrm{hr}$ was carried out for $12 \mathrm{hr}$ at $-15^{\circ} \mathrm{C}$. The ozonide in pentane solution was decomposed by dropwise addition to $500 \mathrm{ml}$ of boiling water to which had been added $40 \mathrm{~g}$ of zinc dust and traces of silver nitrate and hydroquinone. The decomposition was unusually mild and gave $117 \mathrm{ml}$ of aqueous layer and $138 \mathrm{ml}$ of oil layer (which contained some solvent).

The material dissolved in the ether trap was tested for acetaldehyde by introduction of anhydrous ammonia for $5 \mathrm{~min}$. The test was positive, as evidenced by the formation of the characteristic aldehyde-ammonia compound $\left(\mathrm{mp} 86^{\circ}\right.$ to $88^{\circ} \mathrm{C}$ ). A sample of the water layer was treated with dimedon (dimethyldihy droresorcinol), which resulted in a voluminous precipitate of formaldehydedimethone $\left(\mathrm{mp} 189^{\circ}\right.$ to $190^{\circ} \mathrm{C}$ ). A test for acetone by treatment with benzaldehyde [16] failed to produce dibenzalecetone.

The oily layer was fractionated in column 9 to give:

(1) 3-Methyl-2-butanone, bp $92^{\circ}$ to $93^{\circ} \mathrm{C}$, 2,4-dinitrophenyl-hydrazone, $\mathrm{mp} 117^{\circ}$ to $118^{\circ} \mathrm{C}$, 
(2) 3,3-Dimethyi-2-butanone, bp $104^{\circ}$ to $106^{\circ} \mathrm{C}, 2,4$-dinitrophenylhydrazone, $\mathrm{mp} 126^{\circ}$ to $126.5^{\circ} \mathrm{C}$,

(3) 3-Methyl-2-pentanone, bp $117^{\circ}$ to $118^{\circ} \mathrm{C}$, 2,4-dinitrophenylhydrazone, $\mathrm{mp} 67^{\circ}$ to $69^{\circ} \mathrm{C}$.

The 2,4-dinitrophenylhydrazones of these compounds were each tested for identity by the "mixed melting-point" technique. No depressions of melting points were observed when these compounds were mixed with authentic specimens.

(4) Beta-chloropropionic acid (?): At $100^{\circ} \mathrm{C}$ a compound distilled, which solidified to a mush in the condenser. This material was removed, cooled, and filtered to yield a small quantity of white crystals that contained halide (Beilstein's test) and was acidic. These crystals melted at $42^{\circ} \mathrm{C}$. This compound is believed to be betachloropropionic acid, since this melting point agrees well with that listed by Shriner and Fuson [28]. However, it was not definitely identified.

The identification of 3-methyl-2-butanone and acetaldehyde indicates the presence of 3,4-dimethyl2-pentene; the formaldehyde and 3,3-dimethyl-2butanone were formed by splitting of triptene (2,3,3-trimethyl-1-butene); the 3-methyl-2-pentanone and formaldehyde came from 2,3-dimethyl1-pentene.

No 2,4-dimethyl-2-pentene could be detected, since this compound would yield isobutyaldehyde in the oily layer distillation, and no aldehyde derivative was obtained by dimethone tests on the distillate fractions.

\section{Identification and Analyses}

\section{Heptene, Boiling Range $75^{\circ}$ to $100^{\circ} \mathrm{C}$}

The results of the redistillation of the $75^{\circ}$ to $100^{\circ} \mathrm{C}$ cut are shown in figure 3 , and the compounds obtained are enumerated in table 2 , in which a summary of the entire analysis is given, including physical constants measured, methods of identification, and ozonolysis data.

Cut $\mathrm{H}-1$, bp $77.6^{\circ}$ to $77.8^{\circ} \mathrm{C} n_{D}^{20} 1.4034$ to 1.4030: This concentrate was found to contain triptene (2,3,3-trimethyl-1-butene) and comprises about 2 percent of triptene residue. The small quantity of triptene found is material remaining from the original distillation at the Redford Laboratories. The refractive index is higher than the accepted value, due to this plateau being preceded and followed mainly by material of higher refractive index, and undoubtedly it contains some of these higher refractive materials.

Cut $\mathrm{H}-2$, bp $79.5^{\circ}$ to $88.0^{\circ} \mathrm{C}, n_{D}^{20} 1.4025$ to 1.4093: Although this material is intermediate between $\mathrm{H}-1$ and $\mathrm{H}-3$ and contained compounds found in both these cuts, its composition was made even more complex by the presence of other heptenes. A detailed account of the ozonolysis has already been given (section II, 4), in which the cut was found to contain triptene, 3,4-dimethyl-2pentene, and 2,3-dimethyl-1-pentene. Results are given in table 2 .

Cut $\mathrm{H}-3$, bp $89.8^{\circ}$ to $91.8^{\circ} \mathrm{C}, n_{D}^{20} 1.4106$ to 1.4133: The components of this fraction were found to be 3,4-dimethyl-2-pentene and probably 3,4-dimethyl-1-pentene. Ozonolysis gave formaldehyde and acetaldehyde in the water and ether layers, respectively. The oily layer gave 3-methyl2-butanone (see table 2), and an oil boiling $111^{\circ}$ to $112^{\circ} \mathrm{C}$, which contained small quantities of an aldehyde (as shown by reduction of Schiff's reagent), from which only one derivative, the 2,4-dinitrophenylhydrazone, was obtained. This 2,4-dinitrophenylhydrazone, after several recrystallizations, melted at $119.5^{\circ}$ to $121.0^{\circ} \mathrm{C}$. The aldehyde must be a hexaldehyde, since the highestboiling pentaldehyde (normal) boils at $103.7^{\circ} \mathrm{C}$, and the compound in question was derived by removal of a fragment from a heptene. A comparison of these data with those of all the hexaldehydes gave

\begin{tabular}{|c|c|c|}
\hline Compound & Boiling point ${ }^{4}$ & $\begin{array}{l}\text { 2,4-Dinitrophen- } \\
\text { ylhydrazone }\end{array}$ \\
\hline 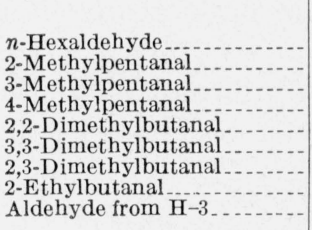 & $\begin{array}{l}{ }^{\circ} C \\
131 \\
119 \text { to } 121[30] \\
121 \\
102 \text { to } 104 \\
102 \text { to } 104 \\
115 \text { to } 117 \ldots \\
117 \text { to } 119 \\
111 \text { to } 112 \ldots \\
\end{array}$ & $\begin{array}{l}104 . \quad \circ \\
103[23] \\
93.5 \text { to } 94.5 \text {. } \\
99 . \\
145 \text {. } \\
147 \text { to } 147 . \\
123 \text { to } 123.5 \text {. } \\
94.5 \text { to } 95.0 . \\
119.5 \text { to } 121.0 \text {. }\end{array}$ \\
\hline
\end{tabular}

4 Data from Brunner and Farmer [3], unless otherwise noted.

These melting point data indicate that the aldehyde from $\mathrm{H}-3$ is 2,3-dimethylbutanal, which, along with formaldehyde, is presumed to be derived from 3,4-dimethyl-1-pentene. The identification of 3-methyl-2-butanone and acetaldehyde show the presence of 3,4-dimethyl-2-pentene.

A sample of cut $\mathrm{H}-3$, when hydrogenated and 
refractionated, gave only 2,3-dimethylpentane (see table 2).

Cut H-4, bp $96.6^{\circ}$ to $97.4^{\circ} \mathrm{C}, n_{D}^{20} 1.4192$ to 1.4206: The major portion of this cut was found to be 2,3-dimethyl-2-pentene, with some 3-ethyl2-pentene. Both components were identified by comparison of their physical properties with those of the pure compounds, and by hydrogentation to the paraffins, followed by a comparison of the paraffins' physical properties with reported values (see table 2). A part of cut $\mathrm{H}-4$ was used to prepare 2,3-dimethylpentane for engine test work. When 9 gal of the cut was hydrogenated and distilled in column 11, 8 gal of high-purity 2,3-dimethylpentane was obtained (see table 2 ). The residue from this distillation was fractionated in column 17 to give $1,230 \mathrm{ml}$ of 3 -ethylpentane with the properties shown in table 2. This 3-ethylpentane must have been derived from 3-ethyl-2-pentene (bp about $95^{\circ} \mathrm{C}$ ) [29], since the only other olefin of this carbon skeleton, 3-ethyl-1-pentene, boils about $10^{\circ} \mathrm{C}$ lower, at $85^{\circ} \mathrm{C}$, with a refractive index of 1.3966 [25].

\section{Octenes, Boiling Range $100^{\circ}$ to $118^{\circ} \mathrm{C}$}

The results from the distillation of the octenes are shown in figures 4 and 5, and analytical results are tabulated in tables 2 and 3. Because of the relatively large hold-up in still 12 , the higher boiling octene components were distilled with the nonene cut (fig. 5). Seven portions of the octenes were designated as cuts $\mathrm{O}_{-1}$ to $\mathrm{O}-7$, as shown in figures 4 and 5 .

Cut $\mathrm{O}-1$, bp $100.4^{\circ}$ to $106.0^{\circ} \mathrm{C}, n_{D}^{20} 1.4158$ to 1.4169: This material was found to be a complex mixture from which only the major component, 3,3-dimethyl-2-ethyl-1-butene, was characterized. On ozonolysis of this cut, only formaldehyde and 2,2-dimethyl-3-pentanone could be identified (see table 2).

Cut $\mathrm{O}-2$, bp $108.3^{\circ}$ to $108.4^{\circ} \mathrm{C}, n_{D}^{20} 1.4170$ to 1.4172: This narrow-boiling fraction was found to be 2,3,3-trimethyl-1-pentene, as evidenced by a comparison of its physical properties with those of this compound previously reported [14]. The sample from the beginning of the plateau showed a boiling range of $0.12^{\circ} \mathrm{C}$ (20 to $80 \%$ distilled), which indicated the presence of some impurity. A portion was hydrogenated, and distillation analysis of the product gave about 93 percent of 2,3,3-trimethylpentane (see table 2) and about 7 percent of 2,2,3-trimethylpentane (bp $110^{\circ} \mathrm{C}$, $\left.n_{D}^{20} 1.4028\right)$. The latter paraffin could have been formed by hydrogenation of 3,3-dimethyl-2-ethyl1-butene, which was identified as a constituent uî the preceding cut $\mathrm{O}-1$.

Cut $\mathrm{O}-3$, bp $109.5^{\circ}$ to $111.2^{\circ} \mathrm{C}, n_{D}^{20} 1.4190$ to 1.4219: The material collected from several runs with the properties designated for $\mathrm{O}_{-3}$ in figure 4 was combined and redistilled in column 13. The composition of the material was found to be complex, but one plateau represented material that is presumed to be 4,5-dimethyl-2-hexene, since a close agreement exists between the properties of the compound isolated and values reported in the literature [7] for 4,5-dimethyl-2-hexene (see table 2).

Cut O-4, bp $112.2^{\circ}$ to $112.3^{\circ} \mathrm{C}, n_{D}^{20} 1.4232$ to 1.4233: This portion of triptene residue was predominantly 3,4,4-trimethyl-2-pentene, as shown by a comparison of its physical properties with those of pure 3,4,4-trimethyl-2-pentene previously obtained [14]. This identification is given additional weight by the fact that when 15 gal of the olefin was oxidized by sodium dichromate-sulfuric acid [14], 3,3-dimethyl-2-butanone was obtained in 30-percent yield, not including a large amount of the same ketone that was recovered as an azeotrope with unreacted olefin.

Cut $\mathrm{O}-5$, bp $112.8^{\circ}$ to $115.0^{\circ} \mathrm{C}, n_{D}^{20} 1.4206$ to 1.4253: Ozonolysis of this cut gave acetaldehyde, acetone, 3-methyl-2-butanone, and 3,3-dimethyl2-butanone. The presence of 3,4,4-trimethyl-2pentene, which gave acetaldehyde and 3,3-dimethyl2-butanone, and 2,3,4-trimethyl-2-pentene, from which acetone and 3-methyl-2-butanone came, is shown. The presence of at least one additional compound is indicated by a dip in the refractive index curve. From the ozonolysis, at least two additional carbonyl compounds, one of which was an aldehyde, bp $113^{\circ}$ to $115^{\circ} \mathrm{C}$ (as shown by reduction of Schiff's reagent) were obtained. Neither of these nor their derivatives could be separated and identified. The 2,4-dinitrophenylhydrazone of this fraction came down as an oil, which, after successive crystallizations, melted $101^{\circ}$ to $105^{\circ} \mathrm{C}$.

Cut $\mathrm{O}-6$, bp $115.9^{\circ}$ to $116.2^{\circ} \mathrm{C}, n_{D}^{20} 1.4262$ to 1.4266: This cut was found to be 2,3,4-trimethyl2-pentene by a comparison of its physical properties with those of pure 2,3,4-trimethyl-2-pentene isolated previously in this laboratory [14] and by 
the identification of 3-methyl-2-butanone and acetone found in the intermediate cut $\mathrm{O}-5$.

Cut $\mathrm{O}-7, \mathrm{bp} 116.8^{\circ}$ to $119.0^{\circ} \mathrm{C}, n_{D}^{20} 1.4266$ to 1.4262: This fraction was found to contain 2methyl-3-ethyl-2-pentene as the major component.

A portion of $\mathrm{O}-7$ was redistilled in column 17 to yield a cut boiling $117.0^{\circ}$ to $118.5^{\circ} \mathrm{C}$. Ozonolysis of a 0.5 -mole sample of this yielded formaldehyde and acetone in the water layer and traces of acetaldehyde in the ether layer. The oily layer proved to be mostly 3-pentanone (see table 2) with a small quantity of a compound boiling $116^{\circ}$ to $119^{\circ} \mathrm{C}$, which gave a 2,4-dinitrophenylhydrazone melting $113^{\circ}$ to $116.5^{\circ} \mathrm{C}$. The latter was not identified. The identification of acetone and 3-pentanone shows the presence of 2-methyl3-ethyl-2-pentene.

Hydrogenation of the redistilled portion of $\mathrm{O}-7$ yielded 2-methyl-3-ethylpentane. (See table 2.)

\section{Nonenes, Boiling Range $121^{\circ}$ to $138^{\circ} \mathrm{C}$}

The results obtained from a typical redistillation of the $121^{\circ}$ to $138^{\circ} \mathrm{C}$ cut (combined with octene residue) are shown in figure 5.

Cut $\mathrm{N}-1$, bp $121.5^{\circ}$ to $123.0^{\circ} \mathrm{C}, n_{D}^{20} 1.4225$ to 1.4186: The major component of this cut was found to be 3,3-dimethyl-2-isopropyl-1-butene, the identification of which was made by a comparison of the physical properties of the olefin and also of the paraffin derived by hydrogenation. The fraction boiling $121.5^{\circ}$ to $123.0^{\circ} \mathrm{C}$ was redistilled in column 17 to give a plateau representing a compound in close agreement in physical properties with those of 3,3-dimethyl-2-isopropyl1-butene previously prepared in this laboratory (see table 2). A portion of this plateau was hydrogenated and distilled in column 17 to give a paraffin with properties almost identical with those of 2,2,3,4-tetramethylpentane [14]. There are only three olefins of this carbon skeleton:

3,3-Dimethyl-2-isopropyl-1-butene, bp $122.21^{\circ}$ C, $n_{D}^{20} 1.4669[14]$

2,3,4,4-Tetramethyl-1-pentene, bp $132^{\circ}$ to $133^{\circ} \mathrm{C}, n_{D}^{20} 1.4275$ [34]. (See cut N-2.)

2,3,4,4-Tetramethyl-2-pentene, bp $>134^{\circ} \mathrm{C}$, $n_{D}^{20}>1.4310$ [33]

It is evident that the paraffin is derived from the first of these olefins.

Cut $\mathrm{N}-2$, bp $127.7^{\circ}$ to $128.1^{\circ} \mathrm{C}, n_{D}^{20} 1.4222$ to
1.4227: This portion of the nonenes was found to contain 2,3,4,4-tetramethyl-1-pentene as the major component. A sample was refractionated in column 17 and a "heart cut" used for measurement of physical properties and for ozonolysis. Ozonolysis gave formaldehyde, and only 3,4,4-trimethyl2 -pentanone in the oily layer, which was identified by the preparation of two derivatives (see table 2 ). When a sample of N-2 was hydrogenated and refractionated, quite pure 2,2,3,4-tetramethylpentane was obtained (see table 2 ). The residue from redistillation of $\mathrm{N}-2$, when ozonized, gave the same products as the main fraction, and, in addition, a small quantity of aldehyde that boiled at $152^{\circ}$ to $158^{\circ} \mathrm{C}$ was found. The 2,4-dinitrophenylhydrazone of this compound melted, after five recrystallizations, at $174.5^{\circ}$ to $176^{\circ} \mathrm{C}$. This compound was not identified.

Cut N-3, bp $133.9^{\circ}$ to $135.5^{\circ} \mathrm{C}, n_{D}^{20} 1.4295$ to 1.4302: Preliminary work on this cut indicated the presence of a complex mixture. The cut was therefore divided into two portions, designated as $\mathrm{N}-3-\mathrm{A}$ and $\mathrm{N}-3-\mathrm{B}$, respectively. Each of these was ozonized separately.

$\mathrm{N}-3-\mathrm{A}$, bp $133.9^{\circ}$ to $134.6^{\circ} \mathrm{C}$, on ozonolysis gave formaldehyde, acetaldehyde, and two ketones boiling at $125^{\circ}$ to $126^{\circ} \mathrm{C}$ and $152^{\circ}$ to $153^{\circ} \mathrm{C}$, which proved to be 2,2-dimethyl-3-pentanone and 3,3,4trimethyl-2-pentanone, respectively (see table 2 ). The presence of a higher boiling aldehyde was detected in the residue from the ketone distillation. The results are interpreted to indicate the presence of 4,4-dimethyl-3-ethyl-2-pentene and 2,3,3,4tetramethyl-1-pentene in cut $\mathrm{N}-3-\mathrm{A}$. The former would, on ozonalysis, give acetaldehyde and 2,2dimethyl-3-pentanone; the latter would give formaldehyde and 3,3,4-trimethyl-2-pentanone.

Cut $\mathrm{N}-3-\mathrm{B}$, bp $134.6^{\circ}$ to $135.6^{\circ} \mathrm{C}$ was ozonized to give formaldehyde, acetaldehyde, 2,2-dimethyl3-pentanone (bp $125^{\circ}$ to $126^{\circ} \mathrm{C}$ ), 3,3,4-trimethyl2-pentanone (bp $152^{\circ}$ to $153^{\circ} \mathrm{C}$ ), and a small amount of 3,4-dimethyl-2-pentanone (bp $136^{\circ}$ to $140^{\circ} \mathrm{C}$ ). (See table 2.) A trace of a higher boiling aldehyde was found in the residue. In addition, a compound boiling $109^{\circ}$ to $114^{\circ} \mathrm{C}$ formed a 2,4-dinitrophenylhydrazone melting $94^{\circ}$ to $96^{\circ}$ C. A "mixed melting point" of the latter with the derivative of 4-methyl-2-pentanone gave a value of $76.5^{\circ}$ to $83^{\circ} \mathrm{C}$; a "mixed melting point" with 2-methyl-3-pentanone gave $88^{\circ}$ to $94^{\circ} \mathrm{C}$. This derivative was not identified. 
The 3,4-dimethyl-2-pentanone, and acetaldehyde, show the presence of 3,4,5-trimethyl-2hexene. The other two ketones found were also present in cut $\mathrm{N}-3-\mathrm{A}$, and were shown to result from 4,4-dimethyl-3-ethyl-2-pentene and 2,3,3,4tetramethyl-1-pentene. The aldehyde trace in the oily layer residue is surmised to be a $\mathrm{C}_{8}$ aldehyde, due to its higher boiling point, which could result from an olefin with the following structure:

$$
\mathrm{C}_{7} \mathrm{H}_{15} \mathrm{CH}=\mathrm{CH}_{2} \text {. }
$$

When cut $\mathrm{N}-3-\mathrm{A}$ and cut $\mathrm{N}-3-\mathrm{B}$ were hydrogenated and distilled, only 2,3,3,4-tetramethylpentane (see table 2) could be obtained in a nearly pure state.

Cut $\mathrm{N}-4$, bp $137.4^{\circ}$ to $137.6^{\circ} \mathrm{C}, n_{D}^{20} 1.4324$ to 1.4328: This fraction was found to contain $3,4,4-$ trimethyl-2-hexene, since ozonolysis yielded only 3,3-dimethyl-2-pentanone and acetaldehyde. (See table 2.) The purity of the compound is indicated by its narrow boiling range, and the absence of complex ozonolysis products. A sample of cut $\mathrm{N}-4$ was hydrogenated to a paraffin, 3,3,4-trimethylhexane, with the physical properties listed in table 2 .

\section{Decenes, Boiling Range $143^{\circ}$ to $163^{\circ} \mathrm{C}$}

'The results of analyses of the decenes are shown in table 2, and data obtained in the distillation are illustrated in figures 5 and 6 . The decene portion proved to be quite complex and the majority of the decenes found in the triptene residue appear to have been formed by polymerization of he original isopentenes.

Cut D-1: This concentrate, boiling range $144^{\circ}$ to $147^{\circ} \mathrm{C}, n_{D}^{20} 1.4300$ to 1.4290 , began to appear as an after run of cut $\mathrm{N}-4$, and was characterized by a drop in the refractive index curve. Since only a small quantity was available, the portion marked D-1 in figures 5 and 6 was redistilled in column 17 , and a portion from the middle of the narrow-boiling cut was used for reaction with ozone. This material was extremely resistant to the action of ozone; after $50 \mathrm{hr}$ of treatment, only 10 percent of the material was converted to ozonide. The presence of acetone, formaldehyde, and 2,2-dimethyl-3-pentanone was established in the decomposition products. (See table 2.) The acetone and 2,2-dimethyl-3-pentanone are presumed to have been formed by splitting $2,2,4$ - trimethyl-3-ethyl-2-pentene. $\mathrm{No}_{9}$ product was isolated as a companion for formaldehyde. A portion of the "best" olefin was hydrogenated and upon distillation proved to be mostly one compound. The properties of this paraffin, 2,2,4trimethyl-3-ethylpentane, are listed in table 2 .

Cut D-2, bp $151.5^{\circ}$ to $155.2^{\circ} \mathrm{C}, n_{D}^{20} 1.4340$ to 1.4356: Ozonolysis of a sample of this fraction gave formaldehyde, acetaldehyde, butanone-2 (bp $80^{\circ}$ to $85^{\circ} \mathrm{C}, 2,4$-dinitrophenylhydrazone $\mathrm{mp}$ and mixed melting point $108^{\circ}$ to $110^{\circ} \mathrm{C}$ ), 3,4,4-trimethyl-2pentanone (see table 2), and a hexaldehyde (bp $110^{\circ}$ to $120^{\circ} \mathrm{C}$ ) which was not completely identified because only a small quantity was present, which was contaminated with some butanone-2. Also present was a trace of an unidentified ketone boiling at $166^{\circ}$ to $168^{\circ} \mathrm{C}$, which gave a 2,4-dinitrophenylhydrazone melting at 160.5 to $162.0^{\circ} \mathrm{C}$, which is presumed to be a $\mathrm{C}_{9}$ ketone.

The identification of acetaldehyde and 3,4,4trimethyl-2-pentanone indicate the presence of 3,4,5,5-tetramethyl-2-hexene. The formaldehyde and the unidentified $\mathrm{C}_{9}$ ketone indicate the presence of a decene with a terminal methylene group attached to a doubly branched carbon. The unidentified hexaldehyde is thought to be 2,2-dimethylbutanal and a companion of butanone-2, which, together, would make up 3,5,5-trimethyl3 -heptene. This presumption is strengthened by hydrogenation studies. Hydrogenation of a sample gave a mixture consisting predominantly of $2,2,3,4$ tetramethylhexane with a lesser quantity of $3,3,5$ trimethylheptane.

Cut D-3, bp $159.0^{\circ}$ to $160.8^{\circ} \mathrm{C}, n_{D}^{20} 1.4372$ to 1.4388: This fraction was a mixture and was found to contain 3,5,5-trimethyl-2-heptene and three other olefins which, on hydrogenation, produced 2,3,3,4-tetramethylhexane, 2,3,4,4-tetramethylhexane, and 2,3,4-trimethyl-3-ethylpentane. (See table 2.)

A 1-gal sample of D-3 was redistilled in column 17 to obtain a purer sample for ozonolysis and hydrogenation. When a portion of the "heart cut" (bp $159^{\circ} \mathrm{C}$ ) of the latter distillation was ozonized, traces of formaldehyde were found in the water layer, and large quantities of acetaldehyde in the ether layer. The majority (about $90 \%$ ) of the oily layer proved to be 4,4-dimethyl2 -hexanone (see table 2 ), with very small quantities of other unidentified higher-boiling materials present, including a $\mathrm{C}_{9}$ aldehyde (as shown by re- 
duction of Schiff's reagent). The ketone was identified by the formation of two derivatives. The semicarbazone, mp $170^{\circ}$ to $171^{\circ} \mathrm{C}$, was formed with great ease, whereas the other semicarbazones made in this work required at least 2 days to crystallize. The 2,4-dinitrophenylhydrazone, $\mathrm{mp} 75^{\circ}$ to $75.5^{\circ} \mathrm{C}$, showed the 4,4-dimethyl2-hexanone to be relatively pure because no extensive recrystallizations of the derivative were needed to reach the final sharp melting point. The melting point for this derivative recorded here agrees with that obtained by Schmerling [27], Laucius [20], and Wheeler (cited by Laucius), but disagrees with that of Drake, Kline, and Rose [8], who obtained a value of $146.5^{\circ}$ to $147^{\circ} \mathrm{C}$. The identification of acetaldehyde and 4,4-dimethyl2 -hexanone prove the presence of 3,5,5-trimethyl2-heptene.

A portion from the same "heart cut" of olefin was hydrogenated and distilled in column 17. Over 90 percent of the charge was recovered as distillate, with the properties the same as those listed for 3,3,5-trimethylheptane in table 2 .

The rest of D-3 was hydrogenated and refractionated in still 11. The major constituent, 3,3,5-trimethylheptane was formed by hydrogenation of the 3,5,5-trimethyl-2-heptene identified previously. Physical constants were measured on this lot. This compound is believed to be of very high purity; the boiling range (20 to 80 percent distilled) was $0.005^{\circ} \mathrm{C}$, the refractive index range of the distillate cut was 0.0001 .

The paraffin residues from 3,3,5-trimethylheptane were distilled in column 17 to give three additional plateaus with the properties shown in table 2, which show the presence of 2,3,4,4-tetramethylhexane, 2,3,3,4-tetramethylhexane, and 2,3,4-trimethyl-3-ethylpentane. The identification of these compounds was made by comparisons of their physical properties with those listed by Francis [13], and by Johnson [17] who found them in the hydrogenated products of the decenes formed from $t$-amyl alcohol and from 2-methyl-2-butane. Presumably the isolated paraffins were derived from the hydrogenation of 2,3,4,4-tetramethyl-2hexene, which is probably a normal methylation product of 3,4,4-trimethyl-2-hexene, of 3,4,4,5tetramethyl-2-hexene, which may be a normal methylation product of 2,3,3,4-tetramethyl-1pentene, and of 3,4-dimethyl-3-isopropyl-1-pentene, which is assigned this structure because of the aldehyde found in the ozonolysis fragments of cut $\mathrm{D}-3$.

The structure of the 3,3,5-trimethylheptane isolated in this work has been conclusively proven by hydrogenation and ozonolysis data. The physical constants of the 3,3,5-trimethylheptane reported herein agree well with those listed by Francis [13] and Johnson [17] but disagree with those of Drake and Welsh [10], who seem to have had an impure substance containing 2,3,3,4tetramethylhexane.

It appears that Drake et al [8] were working with a mixture of olefins. This is borne out by the discordant value of the melting point of the 2,4-dinitrophenylhydrazone of 4,4-dimethyl-2-hexanone. Their value for this derivative, $146.5^{\circ}$ to $147^{\circ} \mathrm{C}$, corresponds to that of 3,3,4-trimethyl-2pentanone [11], which would appear as an ozonolysis product of 3,4,4,5-tetramethyl-2-hexene. The latter has been shown to be a normal constituent of isopentene dimer by recent work of Cook and Stehman [6], who found no other decene of this carbon skeleton boiling in the neighborhood of $159^{\circ} \mathrm{C}$. This indicates that the 2,3,3,4-tetramethylhexane found in the hydrogenated cut D-3 was derived from 3,4,4,5-tetramethyl-2hexene. Although this olefin could have been formed by methylation, as previously indicated, it also could be a dimerization product of the original isopentene, as found by Cook.

In the case of the 2,3,4,4-tetramethylhexane, the olefin parent is believed to be 2,3,4,4-tetramethyl-2-hexene. Of the olefins of this carbon structure studied by Cook, only this compound boiled in the neighborhood of $159^{\circ} \mathrm{C}$. Cook, however, found 2,3,4,4-tetramethyl-2-hexene to be absent from isopentene dimer, and therefore it is probable that this olefin arose by methylation.

The next higher boiling cut, $165^{\circ}$ to $168^{\circ} \mathrm{C}$, is believed to contain undecenes. Although quite resistant to ozone, prolonged treatment of a sample of this material gave formaldehyde and a complex mixture of carbonyl compounds and olefins (bp $159^{\circ}$ to $165^{\circ} \mathrm{C}$ ), from which no pure materials were separated.

\section{Conclusions}

The results obtained in this investigation substantiate the mechanism of olefin methylation as described by Miller and Lovell [22]. While the exact origin of some of the decenes is not clear, it 
has been shown that the methylation reaction proceeds through the decene range, as evidenced by the series of compounds: 3,3-dimethyl-2ethyl-1-butene $\rightarrow 4,4$-dimethyl-3-ethyl-2 -pentene $\rightarrow 2,4,4$-trimethyl-3-ethyl-2-pentene, and also by: 2,3,3-trimethyl-1-pentene $\rightarrow 3,4,4$-trim e th yl 2 -h exene $\rightarrow 2,3,4,4$-tetramethyl-2-hexene.

It is significant that no 2,3,4,4-tetramethyl-2pentene was found. This nonene should be a normal methylation product of 3,4,4-trimethyl-2pentene. It is postulated that this compound is present in an equilibrium mixture with 3,3 dimethyl-2-isopropyl-1-butene, 2,3,4,4-tetramethyl-1-pentene and 2,3,3,4-tetramethyl-1-pentene, and that it occurs as only a small fraction of the equilibrium mixture. The same situation obtains when 2,3,4,4-tetramethyl-3-pentanol is dehydrated [31]. Whitmore and Laughlin [33] found only a trace of the 2-olefin in this mixture of nonenes. It has not been found at all in this laboratory.

The authors acknowledge with appreciation the voluminous prepublication data on the isopentene dimers kindly furnished by Professor Cook at Pennsylvania State College.

\section{References}

[1] H. Adkins, Reactions of hydrogen, chapter III (Univ. of Wisconsin Press, Madison, Wis., 1937).

[2] D. B. Brooks, F. L. Howard, and H. C. Crafton, Jr., J. Research NBS 24, 33 (1940) RP1271.

[3] H. Brunner and E. H. Farmer, J. Chem. Soc. 1039 (1937).

[4] E. T. Cline, Ph D thesis (Ohio State University, 1940).

[5] I. J. Colonge and K. Mostafavi, Bul. Soc. Chim. [5] 6, 335 (1939).

[6] N. C. Cook and C. G. Stehman, Pennsylvania State College, private communication.

[7] Dietrich, Ph D thesis (Ohio State University, 1938).

[8] N. L. Drake, G. M. Kline, and W. G. Rose, J. Am. Chem. Soc. 56, 2076 (1934).

[9] N. L. Drake and F. P. Veitch, J. Am. Chem. Soc. 5\%, 2624 (1935).

[10] N. L. Drake and L. H. Welsh, J. Am. Chem. Soc. 60, 488 (1938).
[11] C. R. Enyeart, Ph D thesis, p. 51 (Pennsylvania State College, 1942).

[12] A. W. Francis, Ind. Eng. Chem. 35, 447 (1943).

[13] A. W. Francis, Ind. Eng. Chem. 36, 256 (1944).

[14] F. L. Howard, T. W. Mears, A. Fookson, P. Pomerantz, and D. B. Brooks, J. Research NBS 38, 365 (1947) RP1779.

[15] E. H. Huntress and S. P. Mulliken, Identification of pure organic compounds, p. 50 (John Wiley \& Sons, New York, N. Y., 1941).

[16] E. H. Huntress and S. P. Mulliken, Identification of pure organic compounds, p. 374 (John Wiley \& Sons, New York, N. Y., 1941).

[17] G. C. Johnson, J. Am. Chem. Soc. 69, 146 (1947).

[18] A. M. Khaletskii, J. Gen. Chem. USSR 8, 164 (1938).

[19] M. S. Kharasch, E. Sternfeld, and F. R. Mayo, J. Org. Chem. 5, 375 (1940).

[20] J. F. Laucius, PhD thesis, tabulation, pp. 161 to 165 (Pennsylvania State College, 1940).

[21] J. R. Lewis and J. L. Simonsen, J. Chem. Soc. 736 (1936).

[22] V. A. Miller and W. G. Lovell, Ind. Eng. Chem. 40, 1138 (1948).

[23] G. T. Morgan and D. V. N. Hardy, Chem. Ind. 52, 519 (1933).

[24] W. A. Mosher, PhD thesis (Pennsylvania State College, 1940).

[25] C. Prevost and J. Daujat, Bul, Soc. chim. [4] 47, 590 (1930).

[26] C. H. Ruof, PhD thesis (Pennsylvania State College, (1948).

[27] L. Schmerling, J. Am. Chem. Soc. 68, 1654 (1946).

[28] R. L. Shriner and R. C. Fuson, The systematic identification of organic compounds, p. 98 (John Wiley \& Sons, Inc., New York, N. Y., 1935).

[29] F. J. Soday and C. E. Boord, J. Am. Chem. Soc. 55, 3296 (1933).

[30] M. Sommelet, Bull. Soc. chim. [4] 1, 406 (1907).

[31] This laboratory, unpublished work.

[32] F. C. Whitmore and J. M. Church, J. Am. Chem. Soc. 54, 3710 (1932).

[33] F. C. Whitmore and K. C. Laughlin, J. Am. Chem. Soc. 55, 3732 (1933).

[34] F. C. Whitmore and W. A. Mosher, J. Am. Chem. Soc. 63, 1122 (1941).

[35] F. C. Whitmore, C. I. Noll, and V. C. Meunier, J. Am. Chem. Soc. 61, 684 (1939).

[36] H. D. Zook, PhD thesis (Pennsylvania State College, 1942).

Washington, October 12, 1948. 